DOI: $10.15593 / 2224-9982 / 2017.48 .11$

УДК 621.454

Н.М. Пивкин

AО «Научно-исследовательский институт полимерных материалов», Пермь, Россия

ВИБРАЦИОННОЕ ГОРЕНИЕ ТВЕРДОТОПЛИВНЫХ ЗАРЯДОВ

В РАКЕТНОМ ДВИГАТЕЛЕ КАК МОДЕЛЬ ПРОЦЕССОВ, ФОРМИРУЮЩИХ

ПРИРОДНЫЕ КАТАСТРОФЫ В АТМОСФЕРЕ ЗЕМЛИ И ОБРАЗОВАНИЕ

КРУПНОМАСШТАБНЫХ ВИХРЕЙ НА ДРУГИХ ПЛАНЕТАХ СОЛНЕЧНОЙ

СИСТЕМЫ

С учетом последних достижений космонавтики произведено сравнение крупномасштабных вихревых образований на четырех планетах Солнечной системы с вибрационным горением твердотопливных зарядов в ракетном двигателе. Показано их сходство по тепловому механизму зарождения, развитию в соответствии с законом вихревого движения Ранка-Хилша и временному периоду существования. Отмечено совпадение некоторых экспериментальных результатов, полученных в ракетном двигателе и земном тропическом циклоне. Сформулированы общие условия возникновения таких вихрей и установлена корреляция между геометрическими размерами планет, вихрей и динамикой ветров в их атмосфере. Для дальнейших исследований предложена физическая модель вибрационного горения твердотопливных зарядов в малогабаритном модельном двигателе с уже отработанной системой измерения параметров рассмотренных образований.

Ключевые слова: твердые ракетные топлива, вибрационное горение, тропические циклоны, вихревые образования в атмосфрере.

N.M. Pivkin

JSC "Research Institute of Polymeric Materials", Perm, Russian Federation

\title{
VIBRATING COMBUSTION OF SOLID ROCKET PROPELLANTS AS A MODEL OF PROCESSES OF THE NATURAL DISASTER GENERATION \\ IN THE EARTH'S ATMOSPHERE AND LARGE-SCALE VORTEX FORMATION ON THE OTHER PLANETS OF THE SOLAR SYSTEM
}

Taking into account the latest achievements of astronautics, a comparison of large-scale vortex structures on the four planets of the solar system with the vibrating combustion of solid fuel charge in a rocket engine has been performed. Their similarity in thermal mechanism of nucleation, development in accordance with the law of vortex motion Ranque-Hilsch, and time period of existence are demonstrated. The matching of some experimental results obtained in a rocket engine and terrestrial tropical cyclone is shown. General conditions of such vortices and a correlation between the geometrical dimensions of the planets, vortices and wind dynamics in their atmosphere are discussed. For further studies a physical model of vibrating combustion of solid propellant in a small model engine with already tested measurement system is proposed.

Keywords: solid rocket propellants, vibrating combustion, tropical cyclones, vortex formation in the atmosphere.

\section{Вибрационное горение топлив}

Вибрационным, или нестабильным, горением твердого топлива в ракетном двигателе принято называть такой режим горения, при котором в камере сгорания развиваются высокочастотные регулярные колебания давления. Как правило, эти колебания приводят к искажению расчетной кривой давление - время и к различного рода нарушениям в работе двигателя: к снижению удельного импульса, резкому усилению (вплоть до разрушения стенок двигателя) или ослаблению (вплоть до прекращения работы заряда) внутрикамерного процесса, повышенному разгару теплоизоляции и соплового аппарата двигателя, а также к интенсивным вибрациям сте- 
нок камеры двигателя, в результате которых может выйти из строя система управления полетом или демонтироваться боевая часть ракеты.

Вибрационное горение на протяжении всей истории пороховой промышленности было крайне нежелательным явлением и затрудняло создание и отработку новых ракетных систем и топлив. Внимание специалистов к этому виду горения не ослабевало в течение нескольких десятков лет, начиная с 1941 г. [1, 2].

В предыдущих работах автором раскрыт механизм зарождения и развития высокочастотных колебаний давления в полости камеры сгорания ракетного двигателя и найдены достаточно эффективные способы их устранения, а в некоторых случаях, наоборот, предложены варианты использования таких колебаний в интересах народного хозяйства $[3,4]$. Было показано, что в зонах горения твердых ракетных топлив имеют место микроколебания давления и электрической проводимости продуктов горения, которые характеризуются частотой 1-16 кГц. Для отдельных топлив регистрируются одновременно ультразвуковые микроколебания частотой 30-250 кГц. Наиболее вероятными причинами этих микроколебаний являются:

- для звукового диапазона (1-16 кГц) - неодновременное выгорание компонентов топлива;

- для ультразвукового диапазона (30-250 кГц) - протекание отдельных газофазных химических реакций в автоколебательном режиме.

На сегодняшний день известно порядка 40 гетерогенных реакций, протекающих в режиме автоколебаний: например, окисление СО, водорода, аммиака, этилена, метанола [5], гидрирование $\mathrm{CO}$, восстановление $\mathrm{NO}$ и т.д.

Специальные эксперименты подтвердили прямую зависимость вибрационного горения твердого топлива от микроколебаний, возникающих в зонах его горения. При благоприятных в резонансном отношении условиях (совпадение или кратность частот) микроколебания «раскачивают» газовую среду, заполняющую полости внутри камеры двигателя, и возбуждают акустические колебания определенной моды по термическому механизму, исследованному академиком Б.В. Раушенбахом [1], который выделил два типа развития колебаний при наличии переменного теплоподвода.

Первый тип основан на принципе Рэлея: если теплота сообщается газу в момент наибольшего сжатия или отнимается от него в момент наибольшего разряжения, то это усиливает колебания. При этом механическая энергия газа, поступая в колебательную систему в том же режиме, в котором осуществляется термодинамический цикл, поддерживает акустические колебания.

По второму типу, при переменном сопротивлении движению газового потока (за счет теплоподвода), из-за изменения его скорости могут возникнуть колебания акустического характера, т.е. в момент увеличения скорости переменная составляющая сопротивления должна разгонять течение, а в момент уменьшения скорости - дополнительно тормозить его.

В первом случае эффект возникновения колебаний связан с фазовым сдвигом между теплоподводом и давлением, а во втором - между теплоподводом и скоростью газового потока.

На основе анализа математических уравнений и численных решений показано, что в качестве энергии для акустических колебаний может использоваться внешний теплоподвод и внутренняя или кинетическая энергия потока [1].

Следует подчеркнуть, что представленный механизм возбуждения акустических колебаний в качестве обязательного элемента предусматривает наличие переменного теплоподвода в рабочей системе. По-видимому, процесс неодновременного выгорания компонентов твердого топлива и протекание отдельных газофазных химических реакций в автоколебательном режиме обеспечивают достаточный теплоподвод для появления вибрационного горения твердотопливного заряда в целом.

На рис. 1 приведены экспериментальные кривые, характеризующие зависимость рабочего давления в камере модельного ракетного двигателя от времени горения твердотопливного заряда для случаев нормального (рис. $1, a$ ) и аномального горения (рис. $1, \sigma)$, вызванного акустическими высокочастотными колебаниями давления тангенциальной моды. 


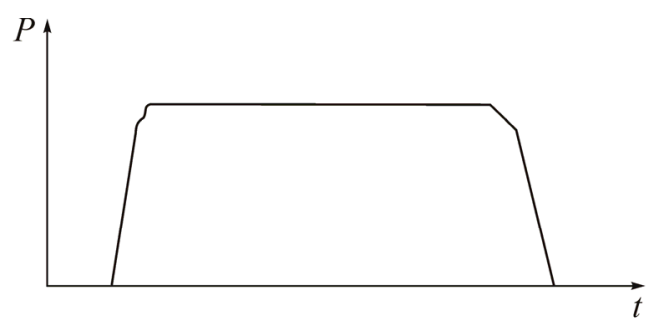

$a$

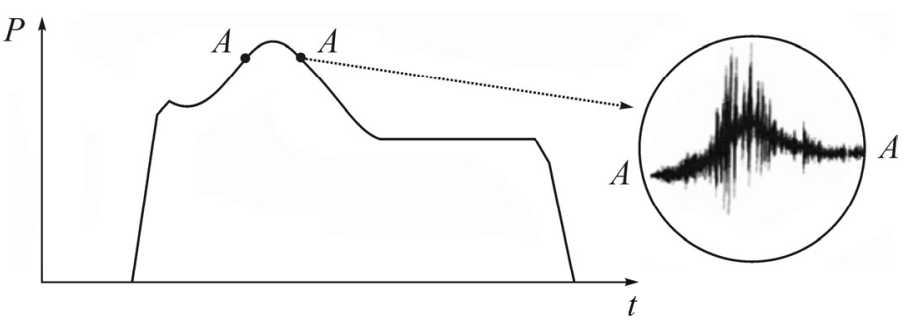

$\sigma$

Рис. 1. Зависимость давления в камере сгорания от времени: $a$ - нормальное горение топливного заряда; $\sigma$ - горение с резким увеличением давления; на врезке - высокочастотные регулярные колебания давления на участке $A-A$, сопровождающие вибрационное горение топлива

На рис. 2 изображен канал заряда при горении: в восьмилучевом канале цилиндрического заряда развиваются акустические колебания тангенциальной моды частотой 9-11 кГц и амплитудой порядка 1 МПа, которые воздействуют на частицы сажи, выделяющиеся при горении. Видна упорядоченность расположения конденсированных частиц сажи в акустическом поле, возникшая в результате их участия в перемещениях, обусловленных колебательным процессом.

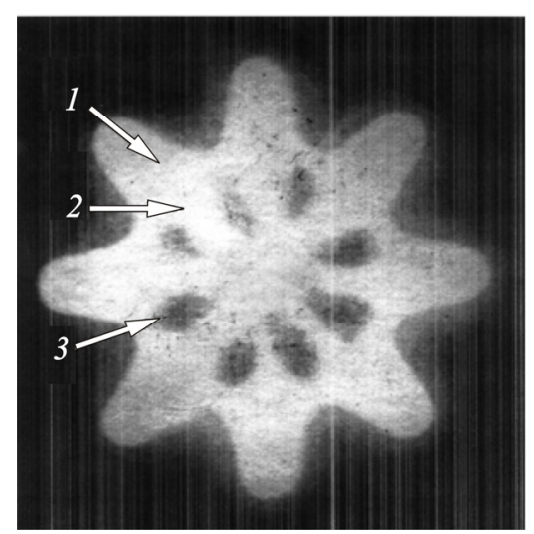

Рис. 2. Когерентное расположение мелкодисперсных конденсированных частиц сажи, выделившихся в результате горения топлива, в акустическом поле при тангенциальных колебаниях вибрационного горения: 1 - восьмилучевой канал цилиндрического заряда; 2 - высокотемпературные газофазные продукты сгорания; 3 - частицы сажи диаметром около 5 мкм. Кадр высокоскоростной видеосъемки процесса горения

Тангенциальные акустические моды колебаний приводят к регулярному вращению продуктов горения вокруг продольной оси ракетного двигателя, при этом температура этих продуктов понижается благодаря эффекту Ранка [6], а следовательно, снижается уровень давления в камере сгорания. Указанное понижение может быть настолько значительными, что происходит полное прекращение горения топливного заряда, как, например, в случае топлив с невысокой температурой горения.

Прямое отношение к вибрационному горению твердых ракетных топлив имеют теория вихревого движения газовых потоков, а также многолетняя практика разработки и внедрения в народное хозяйство страны различных устройств вихревого типа, например холодильных установок [7].

\section{Земные тропические циклоны}

Земные тропические циклоны, которым, как известно, присваивают собственные имена в связи с их огромным влиянием на погоду в планетарном масштабе и с катастрофическими последствиями для многих прибрежных территорий Земли, формируются в тропических широтах в основном над Тихим, Атлантическим и Индийским океанами. 
В фундаментальной работе российских ученых В.Г. Бондура, В.Ф. Крапивина и В.П. Савиных дано описание многочисленных катастроф, возникающих от воздействия циклонов, а также представлены результаты их мониторинга и прогнозирования [8]. Рассмотренное авторами природное явление Эль-Ниньо имеет отношение к стихийным бедствиям, происходящим в экваториальной зоне восточной части Тихого океана. Оно обусловлено комплексом вариаций химических и термобарических параметров атмосферы и океана, а именно резкого повышения температуры воды, падения атмосферного давления в восточной части Тихого океана и существенного изменения направления воздушных потоков. Всё это происходит над одним из наиболее активных участков мирового источника поступления газов с поверхности океана в атмосферу - над Восточно-Тихоокеанской возвышенностью у побережья Перу.

По мнению авторов [8], механизм возникновения Эль-Ниньо и последующих циклонов заключается в следующем. Водород, поднимающийся со дна океана из рифтовой зоны, достигает поверхности океана и за счет выделения тепла при реакции с кислородом нагревает воду верхнего фотического слоя. В результате снижается растворимость $\mathrm{CO}_{2}$ и возрастает поток углекислого газа из океана в атмосферу. Дополнительно к этому возрастает испарение воды, что совместно с $\mathrm{CO}_{2}$ усиливает региональный парниковый эффект. Разогрев воды приводит к зарождению тайфунов, снижению атмосферного давления и нарушению стандартной пассатной схемы атмосферной динамики. Одним из важных регуляторов здесь выступает озоновый слой, разрушение которого или хотя бы временное отсутствие над областью зарождения Эль-Ниньо приводит к возрастанию температурного градиента между экваториальной и южной частями Тихого океана.

Описанный механизм возникновения тропических циклонов может быть дополнен с учетом высокочастотных волновых процессов в океане и над его поверхностью в зоне их зарождения.

В ряде работ показано, что химические реакции окисления водорода и окиси углерода в кислородной среде имеют автоколебательный характер. Измеренная с помощью малоинерционного пьезодатчика частота акустических колебаний давления при горении водорода в кислороде в замкнутом объеме составляет $\sim 1$ кГц [9]. Можно ожидать, что водная поверхность океана в зоне зарождения тропического циклона пульсирует с высокой частотой порядка нескольких килогерц.

По-видимому, в процессе возникновения Эль-Ниньо важную роль играет не только общий поток тепловой и солнечной энергии, но и колебательная составляющая этих величин. Солнце, как отмечают многие исследователи, представляет собой каскад разнообразных газопламенных вихрей и источников акустических колебаний с самыми различными частотами и амплитудами (около 80 млн форм колебаний). По законам физики эти колебания могут взаимодействовать, вплоть до резонанса, со всеми другими колебаниями (в частности, возникающими при Эль-Ниньо), подпитывать их своей большой энергией и приводить в суммарном итоге к таким грозным явлениям природы, как тропические ураганы.

На примере Эль-Ниньо проявляется в конечном итоге природный акустический механизм преобразования тепловой энергии высоконагретых газообразных систем в энергию их вращательного движения.

Сравнение ураганов, вызванных Эль-Ниньо, как и всех тропических ураганов, с вибрационным горением твердых топлив в ракетном двигателе свидетельствуют об их поразительном сходстве по тепловому механизму зарождения, развитию в соответствии с законом вихревого движения и ограниченному по времени периоду существования.

Успехи современной космонавтики позволяют более подробно провести такое сравнение. На космическом снимке тропического урагана Katrina (рис. 3) хорошо видна мощная вихревая система с оптически прозрачной областью в центре, так называемым «глазом». Образуется «глаз», вероятно, в результате коагуляции мелкодисперсных конденсированных частиц, в первую очередь капелек воды, участвующих в вихревом движении, укрупнившихся до размеров 
более 7-8 мкм и выпавших в виде дождя на поверхность океана или суши. Аналогичная картина коагуляции конденсированных частиц в продуктах горения топлива наблюдается при вибрационном горении в ракетном двигателе (рис. 2). В центре вихря отмечено понижение давления и температуры, как и в канале ракетного заряда при вибрационном горении.

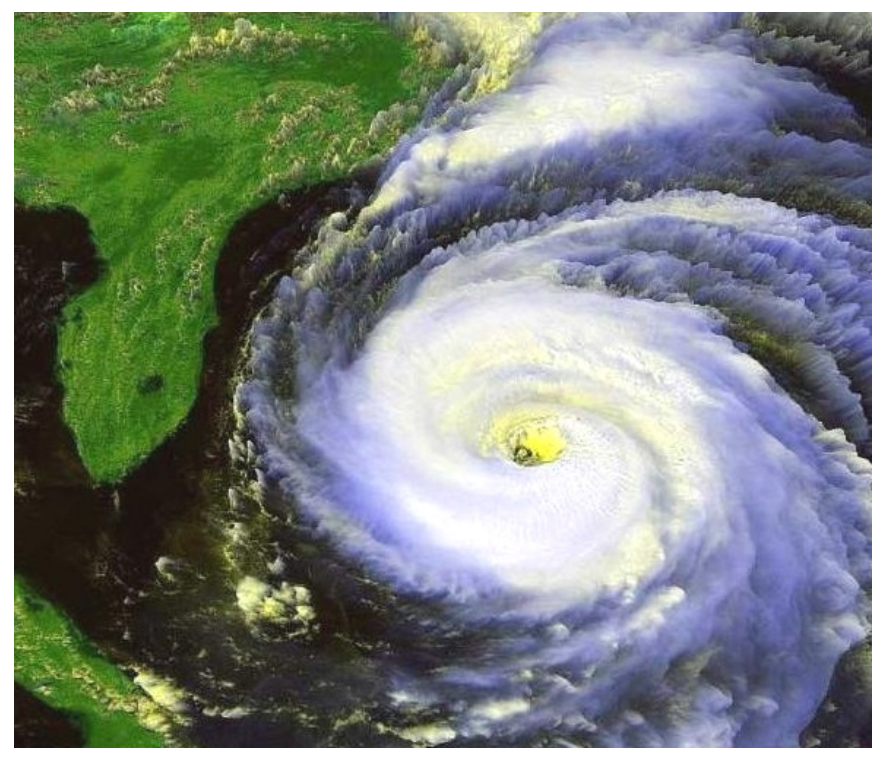

Рис. 3. Общий вид тропического урагана Katrina из космоса (2005 г.)

Интересная деталь, дополнительно свидетельствующая о сходстве процессов. По некоторым исследованиям, в зоне зарождения циклона первоначально образуется не один, а несколько малых вихрей, которые объединяются в большой [10]. Аналогичная картина наблюдается при вибрационном горении многошашечного твердотопливного заряда в модельном ракетном двигателе, когда такое горение одного элемента стимулирует вибрационное горение других и заряда в целом.

К сожалению, пока ученым не удалось напрямую измерить частоты и амплитуды колебаний в момент их возникновения вблизи водной поверхности океана по методическим и техническим причинам. В связи с этим приходится пользоваться данными, полученными при дистанционном зондировании параметров циклонов [11], а также косвенными экспериментальными результатами и сравнениями.

Главным источником возникновения вибрационного горения твердого топлива в ракетном двигателе является достаточно высокая тепловая энергия, которая обеспечивается за счет сгорания топлива в двигателе. Источником энергии природного явления Эль-Ниньо служат химические реакции окисления водорода, поднимающегося со дна океана в локальной зоне, кислородом, содержащимся в морской воде. Эти реакции интенсифицируются повышенным нагревом поверхности океана Солнцем.

Преобразование этой энергии в энергию вихревого движения происходит по механизму термического возбуждения звука через образование систем с развитыми регулярными колебаниями среды при наличии в ней резонансных условий [1]. Для вибрационного горения резонансным условием является совпадение частоты переменного теплоподвода с собственной акустической частотой полости камеры сгорания двигателя по схеме толкающий субъект - качели.

Для природного явления Эль-Ниньо, судя по тому, что оно возникает только периодически, условия резонанса более сложные, но они, безусловно, существуют и частично описаны в работе [8]. Значительную роль при этом, по-видимому, играют коротковолновые акустические колебания от Солнца, поступающие на Землю вместе с потоком фотонов. 
Проблема защиты человечества от негативного влияния тропических циклонов остается пока очень острой и актуальной. В работах $[12,13]$ обсуждаются различные методы воздействия на эти циклоны, в их числе: сокращение поступления водяного пара как носителя тепла из океана в атмосферу, создание искусственного апвеллинга, понижающего температуру поверхности океана в районе зарождения тропического циклона, снижение напряженности электрического поля в облачной структуре урагана.

Надежным и проверенным в условиях гашения высокочастотных колебаний давления в ракетном двигателе при вибрационном горении топлива является подход, связанный с применением распыления мелкодисперсных конденсированных частиц (твердых или жидких) в области зарождения циклона.

На современном этапе исследований необходимо экспериментально определять частоту колебаний теплоприхода вблизи поверхности океана, где зарождается бедствие. Частота колебаний должна регистрироваться с помощью малоинерционных датчиков давления или температуры. Данная или кратная ей частота позволит выбрать оптимальный диаметр частиц засеиваемых реагентов для гашения (диссипации энергии) рассматриваемых колебаний по законам акустики, а также наметить пути исследования факторов, которые могут вступать в резонанс с переменным теплоприходом в образовавшейся автоколебательной системе.

Оптимальный размер частиц для гашения колебаний определяется на основе решения уравнений Навье-Стокса и зависит от частоты колебаний теплоприхода в автоколебательной системе.

Оптимальный диаметр капель воды $d$ для гашения колебаний в зависимости от частоты колебаний теплоприхода $f$ в автоколебательной системе [4]

\begin{tabular}{|l|c|c|c|c|c|c|c|c|c|c|c|c|}
\hline$f$, кГц & 0,2 & 0,5 & 0,7 & 0,9 & 2,0 & 4,0 & 5,0 & 6,0 & 7,0 & 8,0 & 9,0 & 10,0 \\
\hline$d$, мкм & 16,2 & 10,2 & 8,7 & 7,6 & 5,1 & 3,6 & 3,2 & 2,9 & 2,7 & 2,5 & 2,4 & 2,3 \\
\hline
\end{tabular}

Как показывает многолетний опыт борьбы с нежелательным вибрационным горением твердых топлив в ракетном двигателе, для устранения или хотя бы ослабления тропических циклонов, подобных возникающим при Эль-Ниньо, засеивание частицами реагентов оптимального размера должно производиться вблизи водной поверхности океана, т.е. там, где рассматриваемое явление зарождается.

Для повышения эффективности диссипации потенциальной энергии набирающего силу тропического циклона засеивание частицами реагентов в области его зарождения можно сочетать с размещением там же надводных устройств, использующих или преобразующих ветровую энергию, предназначенных для рассеивания основного ветряного потока зарождающегося урагана [14].

\section{Вихревые образования на других планетах Солнечной системы}

Обратимся к вихревым образованиям на других планетах Солнечной системы. По аналогии с Землей обязательными условиями появления вихревых образований на любой планете должно быть: наличие газообразной оболочки, зарождение или постоянное присутствие регулярных волновых импульсов тепла, вступление этих импульсов в резонанс с колебаниями, внешними по отношению к планете или внутренними - от внутренних источников тепловой энергии, развитие тепловых колебаний по закону вихревого движения Ранка-Хилша.

Наибольший интерес для сравнения с земными условиями представляет планета Венера, ветры в атмосфере которой, состоящей из углекислого газа и облаков сероводорода, достигают скорости в 60 раз большей, чем скорость вращения самой планеты, что получило название «супервращение». Относительная близость к Солнцу, быстрое вращение атмосферы (скорость вет- 
ра в верхних слоях более 100 м/с), отсутствие магнитного поля и поглощение солнечного излучения преимущественно в ультрафиолетовом диапазоне обеспечивают достаточно высокую температуру ее поверхности и атмосферы (рис. 4).

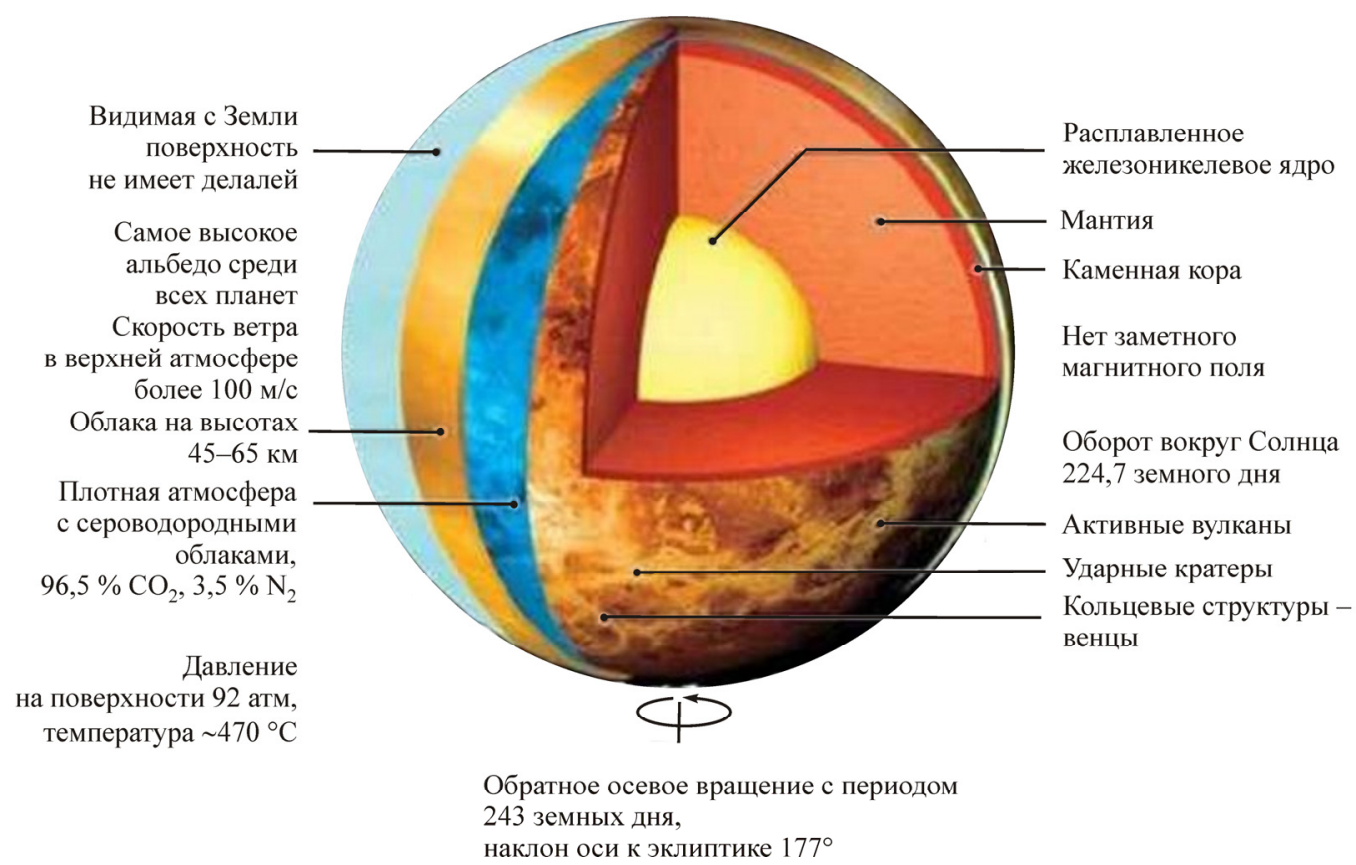

Рис. 4. Строение и основные параметры Венеры

Исследования Венеры с помощью спутника «Венера-Экспресс» и других космических аппаратов позволили получить изображения планеты в ультрафиолетовой, инфракрасной и видимой частях спектра, а также установить особенности вихревых образований в ее атмосфере [15].

Оказалось, что над южным полюсом этой планеты располагается центр действия ее газовой оболочки. Атмосферный вихрь, который вчетверо больше земных циклонов, вращается, то распадаясь, то формируясь снова, ежедневно меняя свою форму. Вихрь принято называть «двойным» по числу «глаз». Возможно, это два независимых образования, сосредоточенных около южного полюса.

Достаточно четкое изображение одной из фаз венерианского вихря представлено на рис. 5 , где для сравнения приведено также изображение земного урагана Katrina. По структуре оба вихря практически совпадают, за исключением размеров (таблица). Для «глаза» Венеры в центре вихря на высоте порядка 60 км от поверхности зарегистрирована температура $250 \mathrm{~K}$, которая свидетельствует об охлаждении атмосферы по закону Ранка и для этой планеты.

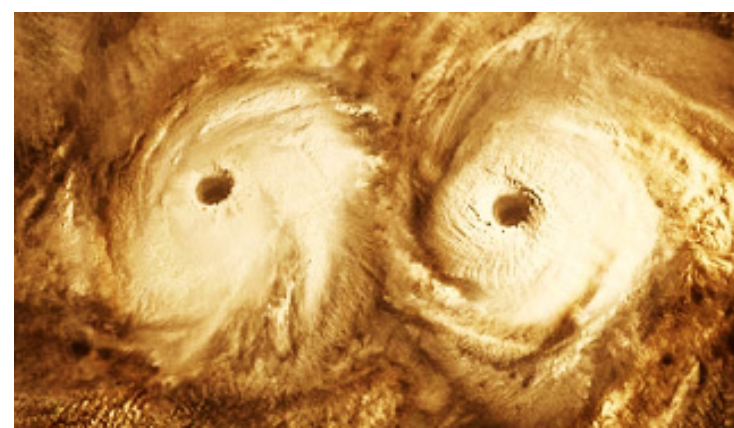

$a$

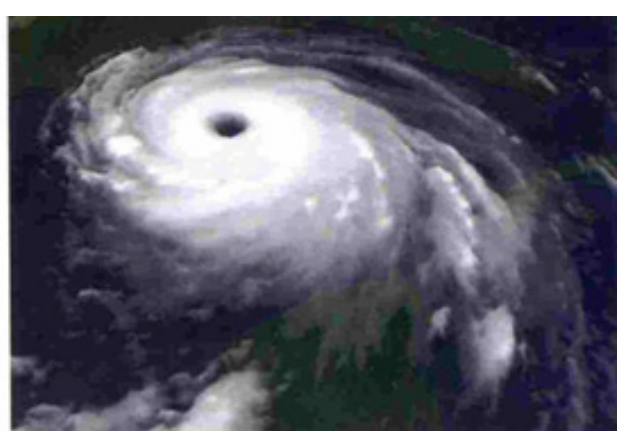

6

Рис. 5. Вихри на южном полюсе Венеры (a) и на Земле (б) 
Горение твердотопливных зарядов в РД как модель процессов, формирующих природные катастрофы

Приблизительные размеры и скорость вихря на различных планетах

\begin{tabular}{|l|l|c|c|c|}
\hline \multicolumn{1}{|c|}{ Планета } & \multicolumn{1}{|c|}{ Название вихря } & $\begin{array}{c}\text { Диаметр вихря, } \\
\text { км }\end{array}$ & $\begin{array}{c}\text { Диаметр «глаза», } \\
\text { км }\end{array}$ & $\begin{array}{c}\text { Максимальная } \\
\text { скорость вихря, км/ч }\end{array}$ \\
\hline Земля & Ураган Каtrina & 700 & 60 & 260 \\
\hline Венера & Вихрь Южного полюса & 1000 & 125 & 400 \\
\hline Сатурн & Атмосферный вихрь & 30000 & 3160 & 320 \\
\hline Юпитер & Большое красное пятно & 40000 & 13000 & 540 \\
\hline
\end{tabular}

В таблице приведено сравнение приблизительных параметров вихревых образований на различных планетах Солнечной системы. Просматривается корреляция между геометрическими размерами планет, вихрей и динамикой их ветров. Чем больше планета и скорость ветров в ее атмосфере, тем масштабнее вихрь и тем больше диаметр «глаза». «Глаз» вихря наблюдается на каждой планете, независимо или в слабой зависимости от ее размера, химического состава, давления и температуры атмосферы. Отметим, что эффект Ранка в земных условиях также слабо зависит от химического состава, давления и температуры используемой для экспериментов газовой среды.

Поражающие воображение снимки, полученные с помощью космического аппарата Кассини, представленные на рис. 6, свидетельствуют об интенсивных вихревых образованиях на планетах-гигантах Сатурне и Юпитере [16].

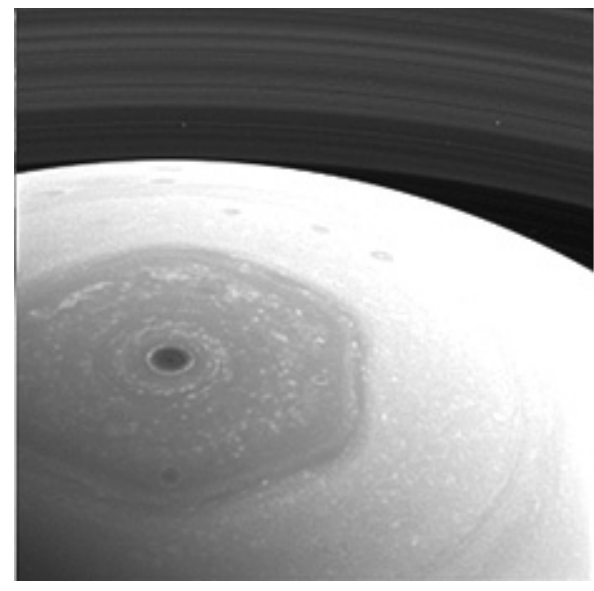

$a$

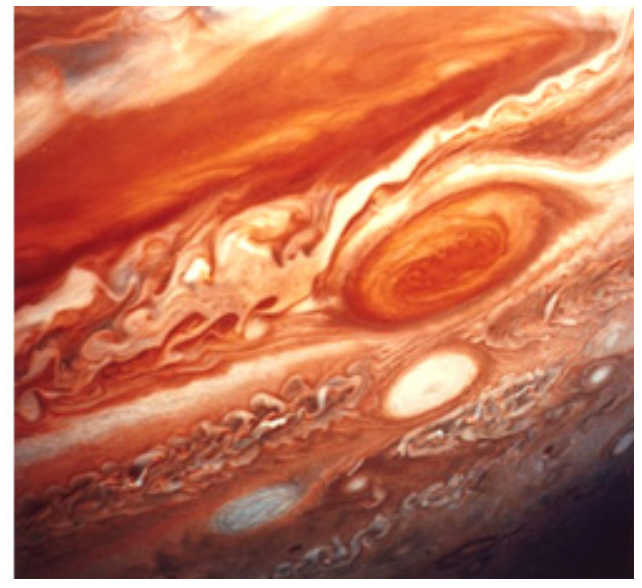

6

Рис. 6. Атмосферные вихревые образования на Сатурне (a) и Юпитере (б). Ярко-оранжевый цвет Большого красного пятна на Юпитере связан с наличием серы и фосфора в его атмосфере

Атмосфера Сатурна состоит в основном из водорода и гелия, а верхний слой облаков образован замерзшим аммиаком, ниже которого расположены облака из гидросульфида аммония. По мере погружения в глубину водородная атмосфера Сатурна становится всё плотнее и горячеe, пока, наконец, на расстоянии около половины радиуса и давлении около $3 \cdot 10^{6}$ атм молекулярный водород не перейдет в металлическую форму. В атмосфере Сатурна наблюдаются вихревые образования, диаметр которых достигает 30000 км, а скорость ветра - свыше 300 км/ч; в центре вихря вращается воронка диаметром 3160 км, являющаяся «глазом» вихря (см. рис. 6).

Повышенный научный интерес представляет Большое красное пятно на Юпитере, известное уже более 350 лет, размер которого составляет около 40000 км. По мнению ученых, это самый большой вихрь в Солнечной системе со скоростью ветров 540 км/ч. Площадь пятна продолжает сокращаться, а его очертания постепенно принимают более округлую форму [16].

В заключение отметим, что недавно астрономы, работающие с космическими телескопами NASA Spitzer и Kepler, обнаружили, что на одном из полюсов звезды W 1906+40 бушует ги- 
гантский облачный шторм (рис. 7), похожий на Большое красное пятно Юпитера [17]. То, что облачные бури характерны для некоторых планет, уже давно было известно ученым. Однако это первое явное свидетельство подобного явления на звезде. Инфракрасные измерения телескопа на двух длинах волн указали на наличие бури. Исследователи полагают, что на этой звезде вполне может идти дождь из горячего песка, расплавленного железа или солей.

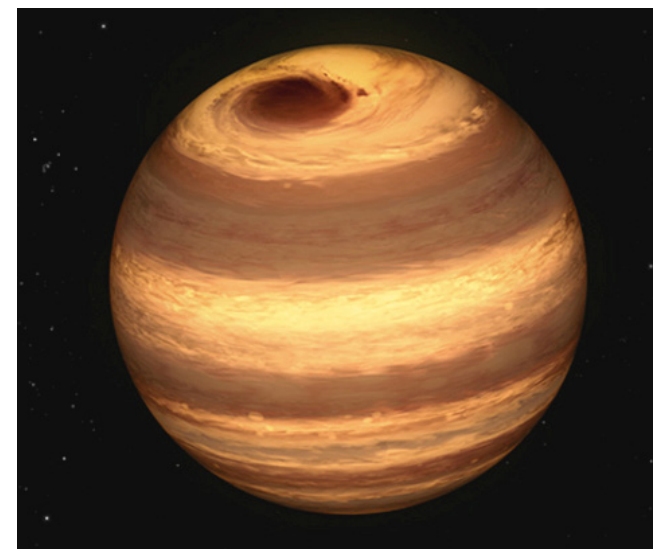

$a$

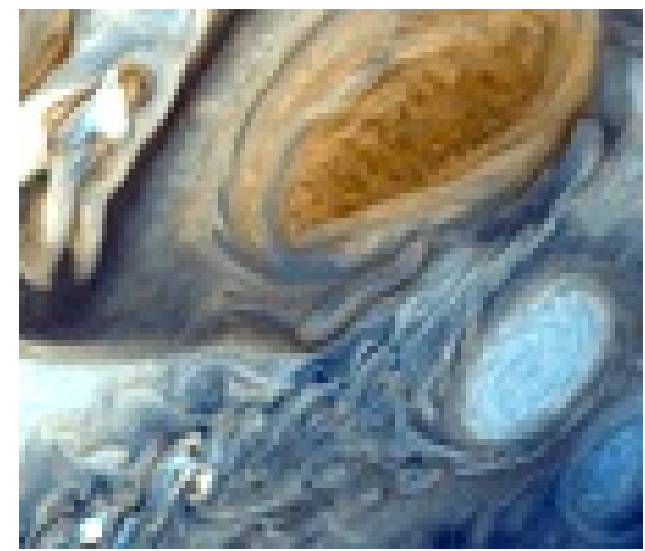

6

Рис. 7. Облачный шторм на звезде W 1906+40: $a$ - общий вид вихря около полюса звезды; $\sigma$ - увеличенное изображение того же вихря, сходное с Большим красным пятном на Юпитере

Температура данной звезды составляет около $1930{ }^{\circ} \mathrm{C}$, что близко к температуре газовой среды в модельном ракетном двигателе с вибрационным горением заряда, где также наблюдается образование вихрей с когерентным расположением мелкодисперсных конденсированных частиц продуктов горения топлива.

\section{Заключение}

Впервые произведено сравнение вибрационного горения твердых топлив в ракетном двигателе с природным процессом образования тропических циклонов в атмосфере Земли как двух автоколебательных систем. Сравнение показывает, что обе системы имеют сходство по тепловому механизму зарождения, развитию в соответствии с законом вихревого движения РанкаХильша и временному периоду существования.

Предложен уточненный механизм образования земных тропических циклонов, включающий в себя, дополнительно к известным представлениям, важную роль акустических колебательных процессов в зонах зарождения циклонов вблизи водной поверхности тропических океанов.

Главным источником возникновения тропического циклона является очень большая тепловая энергия, которая обеспечивается за счет повышенного нагрева водной поверхности океана Солнцем и за счет химических реакций окисления водорода, поднимающегося со дна океана, кислородом, содержащимся в морской воде. Преобразование этой энергии в энергию вихревого движения происходит, предположительно, по механизму термического возбуждения звука через образование систем с развитыми регулярными колебаниями среды при наличии в ней резонансных условий. Значительную роль при этом должны играть коротковолновые акустические колебания от Солнца, поступающие на Землю вместе с потоком фотонов, а также за счет автоколебательного характера химической реакции окисления водорода в морской воде.

Земной тропический циклон - это очень большое энергетическое образование, которое после Солнца занимает второе место на нашей планете. С точки зрения физики трудно объяснить его возникновение без участия высокочастотных колебательных процессов, способных создавать высочайшую концентрацию тепловой энергии за счет взаимодействия колебаний 
друг с другом и последующего резонанса. Следует ожидать уровень резонансных частот в пределах килогерц. Однако проблема более точного определения частоты и амплитуды колебаний в тропических циклонах с помощью малоинерционных датчиков остается весьма актуальной.

Сравнение масштабных вихревых образований на четырех планетах Солнечной системы свидетельствует об их единой природе. Это позволяет сформулировать общие условия возникновения таких вихрей на планетах:

- наличие атмосферы (газообразной оболочки);

- зарождение или постоянное существование на планете регулярных волновых импульсов тепловой энергии (тепловых колебаний);

- вступление этих импульсов в резонанс с колебаниями от внешних или внутренних по отношению к планете источников тепла;

- развитие колебаний по вихревому механизму Ранка-Хилша.

Наблюдается корреляция между геометрическими размерами планет, вихрей и динамикой их ветров. Чем больше планета и скорость ветров в ее атмосфере, тем масштабнее вихрь, «глаз» и, по-видимому, общий запас тепловой и кинетической энергии.

Предложенная модель вибрационного горения твердотопливных зарядов в ракетном двигателе может оказаться весьма полезной для исследования малопонятных или малоизученных к настоящему времени особенностей вихревых движений как на Земле, так и на других планетах Солнечной системы.

\section{Библиографический список}

1. Раушенбах Б.В. Вибрационное горение. - М.: Физматлит, 1961. - 500 с.

2. Culick F.E.C. Unsteady motions in combustion chambers for propulsion systems / California Institute of Technology. - RTO NATO, 2006.

3. High-frequency instability of combustion in solid rocket motors / N.M. Pivkin [et al.] // Journal of Propulsion and Power. - 1995. - Vol. 1, № 4. - P. 651-656.

4. Пивкин Н.М. Проектирование внутрикамерных процессов в ракетном двигателе на твердом топливе. - Пермь: Пресс-тайм, 2009. - 65 с.

5. Сараев А.А. Природа автоколебаний в реакциях каталитического окисления легких алканов (метан, пропан) на никелевом катализаторе: дис. ... канд. физ.-мат. наук. - Новосибирск, 2016.

6. Гуцол А.Ф. Эффект Ранка // Успехи физических наук. - 1997. - Т. 176, № 6. - С. 665-687.

7. Меркулов А.П. Вихревой эффект и его применение в технике. - М.: Машиностроение, 1969. - $185 \mathrm{c}$.

8. Бондур В.Г., Крапивин В.Ф., Савиных В.Т. Мониторинг и прогнозирование природных катастроф. - М.: Научный мир, 2009. - 692 с.

9. Пушкарев А.И., Ремнев Г.Е. Колебательный характер процесса окисления водорода при инициировании импульсным электронным пучком // Физика горения и взрыва. - 2005. - Т. 41, № 4. - С. 18-21.

10. Алексеев В.В., Киселева С.В., Лаппо С.С. Лабораторные модели физических процессов в атмосфере и океане. - М.: Наука, 2005. -312 с.

11. Пудов В.Д. Возможные пути снижения рисков разрушительного воздействия ураганов (тайфунов) // Проблемы анализа риска. - 2008. - Т. 5, № 1. - С. 62-71.

12. Alamaro M., Michele J., Pudov V. A preliminary assessment of inducing anthropogenic tropical cyclones using compressible free jets and the potential for hurricane mitigation // Journal of Weather Modification. 2006. - Vol. 38, № 1. - P. 82-96.

13. Нерушев А.Ф. Механизмы и эффекты воздействия интенсивных атмосферных вихрей на озоновый слой: дис. ... д-ра физ.-мат. наук. - Обнинск, 2001. - 241 с.

14. Способ ослабления тропических циклонов: пат. Рос. Федерация № 2541659 / Пивкин Н.М., Голубев А.Е., Пивкин А.Н. 15.01.2015.

15. Piccioni Y., Drossart P. South-polar features on Venus similar to those near the North Pole // Nature. 2007. - Vol. 450, iss. 7170. - P. 637-640.

16. The global vortex analysis of Jupiter and Saturn based on Cassini Imaging Science Subsystem / H.J. Trammell, L. Li, X. Jiang, M. Smith [et al.] // Icarus. - 2014. - № 242. - P. 122-129. 
17. Kepler monitoring of an 1 dwarf. II. Clouds with multi-year lifetimes / J.E. Gizis [et al.] // The Astrophysical Journal. - 2015. - Nov. 10. - Vol. 813. - P. 104 (10 p.).

\section{References}

1. Raushenbakh B.V. Vibratsionnoe gorenie [Vibrating combustion]. Moscow, Fizmatlit, 1961, 500 p.

2. Culick F.E.C. Unsteady motions in combustion chambers for propulsion systems. California Institute of Technology: RTO NATO, 2006.

3. Pivkin N.M. et al. High-frequency instability of combustion in solid rocket motors. Journal of Propulsion and Power, 1995, vol. 1, no. 4, pp. 651-656.

4. Pivkin N.M. Proektirovanie vnutrikamernykh protsessov v raketnom dvigatele na tverdom toplive [Designing chamber processes in solid propellant rocket motor]. Perm, Press-taym, 2009, 65 p.

5. Saraev A.A., Priroda avtokolebaniy v reaktsiyakh kataliticheskogo okisleniya legkikh alkanov (metan, propan) na nikelevom katalizatore [Nature of self-oscillaltions in the reactions of catalytic oxidation of light alkanes (methane, propane) with nickel catalyst]. Ph. D. thesis. Novosibirsk, Institut kataliza im. G.K. Boreskova SO RAN, 2016.

6. Gutsol A.F. Effekt Ranka [Ranque effect]. Uspekhi fizicheskikh nauk, 1997, vol. 176, no. 6, pp. 665-687.

7. Merkulov A.P. Vikhrevoy effekt i ego primenenie $v$ tekhnike [Swirling effect and its application in engineering]. Mocow, Mashinostroenie, 1969, 185 p.

8. Bondur V.G., Krapivin V.F., Savinykh V.T. Monitoring i prognozirovanie prirodnykh katastrof [Monitoring and forecasting natural disasters]. Moscow, Nauchnyy mir, 2009, 692 p.

9. Vibrational character of the hydrogen-oxidation process initiated by a pulsed electron beam. Combustion, Explosion, and Shock Waves, 2005, vol. 41, no. 4, pp. 375-378.

10. Alekseev V.V., Kiseleva S.V., Lappo S.S. Laboratornye modeli fizicheskikh protsessov v atmosfere i okeane [Laboratory models of the physical processes in the atmosphere and the ocean]. Moscow, Nauka, 2005, $312 \mathrm{p}$.

11. Pudov V.D. Vozmozhnye puti snizheniya riskov razrushitelnogo vozdeystviya uraganov (tayfunov) [Possible ways to mitigate the devastating impact of hurricanes (Typhoons)]. Problemy analiza riska, 2008, vol. 5, no. 1, pp. 62-71.

12. Alamaro M., Michele J., Pudov V. A preliminary assessment of inducing anthropogenic tropical cyclones using compressible free jets and the potential for hurricane mitigation. Journal of Weather Modification, 2006, vol. 38, no. 1, pp. 82-96.

13. Nerushev A.F. Mekhanizmy i effekty vozdeystviya intensivnykh atmosfernykh vikhrey na ozonovyy sloy [Mechanisms and effective impacts of intensive atmospheric vortexes on ozone layer]. Doctor's degree dissertation. Obninsk, Tayfun, 2001, 241 p.

14. Pivkin N.M., Golubev A.E., Pivkin A.N. Sposob oslableniya tropicheskikh tsiklonov [The way to reduce tropical cyclones]. Rossiyskaya Federatsiya no. 2541659, 2015.

15. Piccioni Y., Drossart P. South-polar features on Venus similar to those near the North Pole. Nature, 2007, vol. 450, iss. 7170, pp. 637-640.

16. Trammell H.J., Li L., Jiang X., Smith M., et al. The global vortex analysis of Jupiter and Saturn based on Cassini Imaging Science Subsystem. Icarus, 2014, no. 242, pp. 122-129.

17. John E. Gizis, et al. Kepler monitoring of an 1 dwarf. II. Clouds with multi-year lifetimes. The Astrophysical Journal, 2015, vol. 813, p. 104.

\section{Сведения об авторе}

Пивкин Николай Матвеевич (Пермь, Россия) - доктор технических наук, профессор, заместитель заведующего отделом АО «Научно-исследовательский институт полимерных материалов» (614113, г. Пермь, ул. Чистопольская, д. 16, e-mail: pivkin1@ @ail.ru).

\section{About the author}

Nickolai M. Pivkin (Perm, Russian Federation) - Doctor in Technical Sciences, Professor, Deputy Head of Department, JSC "Scientific-Research Institute of Polymeric Materials" (16, Chistopolskaya st., Perm, 614113, Russian Federation, e-mail: pivkin1@ mail.ru).

Получено 16.12.2016 